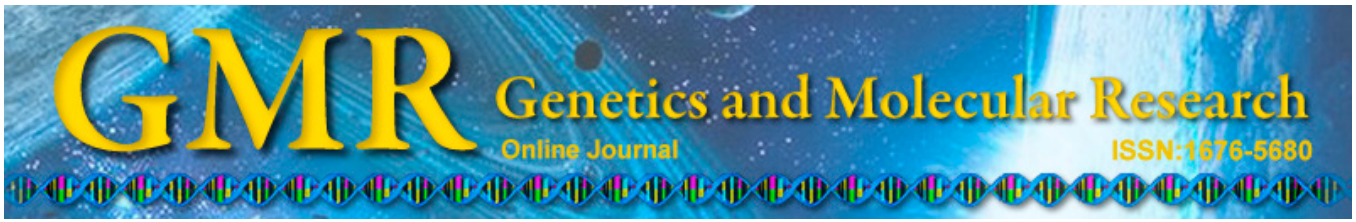

\title{
Plasma exchange parameter selection and safety observation of children with severe ricinism
}

\author{
G.M. Chen, Z.H. Yu, X.J. Nie, Z. Li, Z.W. Sun, Z.F. Weng, Y.Y. Yang, \\ S.L. Chen, C.F. Wang, S.R. Zheng, Y.Y. Luo, Y.T. Lu, \\ H.Q. Cao and H.X. Zhan \\ Department of Pediatrics, \\ Fuzhou General Hospital of Nanjing Military Command, PLA, \\ Clinical Medical College of Fujian Medical University, \\ Affiliated Dongfang Hospital of Xiamen University, Fuzhou, China \\ Corresponding author: G.M. Chen \\ E-mail: guangmingchencn@163.com
}

Genet. Mol. Res. 14 (2): 4169-4176 (2015)

Received May 22, 2014

Accepted September 24, 2014

Published April 27, 2015

DOI http://dx.doi.org/10.4238/2015.April.27.32

\begin{abstract}
The aim of this study was to investigate the selection of plasma exchange (PE) parameters and the safety of children with severe ricinism. The PE parameters and heparin dosage in 7 children with severe ricinism were recorded, and changes in the patients' vital signs and coagulation function were monitored before and after PE. All patients successfully completed PE. The speed of blood flow was 50$80 \mathrm{~mL} / \mathrm{min}$, speed of exchange flow was $600-800 \mathrm{~mL} / \mathrm{h}$, and isolating rate of blood plasma was $12.5-19.05 \%$. Transmembrane pressure was stable at approximately $100 \mathrm{mmHg}$, and venous pressure was stable at approximately $95 \mathrm{mmHg}$. The first dose of heparin was $0.39 \pm 0.04 \mathrm{mg} /$ $\mathrm{kg}$, and the maintaining heparin dose was $0.40 \pm 0.05$ to $0.22 \pm 0.03$ $\mathrm{mg} \cdot \mathrm{kg}^{-1} \cdot \mathrm{h}^{-1}$. During the PE process, mean arterial pressure, heart rate, respiratory rate, and pulse oxygen saturation were steady. After PE, the activated partial thromboplastin time and thrombin time prolonged to
\end{abstract}


2-3 times greater than that before PE. However, no bleeding tendency was seen. For children with severe ricinism, the choice of PE to eliminate the toxin from blood, tissues, and organs was safe and effective.

Key words: Ricinus communis; Ricinism; Plasma exchange (PE); PE parameters; Rescue treatment

\section{INTRODUCTION}

Ricinus communis refers to the seed of $R$. communis L., which contains two toxic ingredients, ricin and ricinine. Ricin is a cell protoplasmic poison with high toxicity, capable of damaging the parenchyma of the liver and kidneys in a short time, thus resulting in swelling, bleeding, and necrosis; it also aggregates and dissolves red blood cells, paralyzing the respiratory center and vasomotor center, and if rescue therapy is delayed, can lead to very serious consequences (Audi et al., 2005; Lim et al., 2009; Assiri, 2012). To date, no specific antidote or vaccine for ricin poisoning exists (Hu et al., 2012). Consequently, treatment primarily consists of induction of vomiting, gastric lavage, and catharsis, with some cases requiring a high enema (Musshoff and Madea, 2009; Buonocore et al., 2011) to quickly clear residual toxins from the digestive tract. However, general medical treatments cannot effectively clear toxins that have already entered the blood, tissues, or organs, especially in cases of multiple organ dysfunction. Plasma exchange (PE) is a blood purification method that removes blood from the body, then separates and removes the plasma in vitro and reinfuses an equal amount of exchange fluid back into the body. PE has played a major role in rescue treatment of critically ill patients and patients with autoimmune diseases (Inoue et al., 2010; Qiu et al., 2011; Qu et al., 2011). It is especially valuable in diseases associated with liver failure because of its demonstrated irreplaceable role in clearing toxins from the liver (Nakae et al., 2012). Theoretically, PE could clear almost all toxins from the plasma, especially those that couple tightly with plasma proteins (Schutt et al., 2012). When children, who have immature immune systems, are poisoned by ricin, the toxins should be removed as early and quickly as possible to reduce subsequent damage, mortality, and sequelae. However, because of difficult vascular access, higher technical requirements for anticoagulation, and the fear of hemodynamic changes, serum response, and transfusion-transmitted diseases, PE has rarely been used for rescue treatment of acute poisoning in children. In our hospital, 7 children with severe ricinism were treated with PE in November 2012, and all were cured without any organ system dysfunction or sequelae. In this paper, we report on parameter selection and safety during PE.

\section{SUBJECTS AND METHODS}

\section{Clinical data}

The 7 patients in this study were all school-age children, including 6 boys and 1 girl. Ages ranged from 7 years and 7 months to 8 years and 11 months, with a mean age of $8.17 \pm$ 0.42 years. The lowest weight was $22.00 \mathrm{~kg}$, and the highest was $31.20 \mathrm{~kg}$, with a mean weight of $25.69 \pm 3.17 \mathrm{~kg}$. Except for one child who had an upper respiratory tract infection before eating the $R$. communis, the children were all healthy. The amount of raw $R$. communis mistakenly eaten was 5 to 12 pills. This study was conducted in accordance with the Declaration of 
Helsinki and with approval from the Ethics Committee of Fuzhou General Hospital of Nanjing Military Command, PLA. Written informed consent was obtained from all participants.

\section{Clinical manifestations}

All the children in the study exhibited symptoms within 3 to $4 \mathrm{~h}$ after ingestion of R. communis. Gastrointestinal symptoms occurred first, appearing as nausea, vomiting and abdominal pain. The degree of vomiting varied from several times to more than 10 times. Four children developed diarrhea, and 1 child exhibited hemorrhagic colitis as the primary symptom. In addition to the gastrointestinal symptoms, a common manifestation was the appearance of cardiac symptoms: slowing of the heart rate, sinus arrhythmia, occasional atrial premature beats, and in 1 patient, significant bradycardia. Two children developed fever, with a body temperature of $38^{\circ}$ to $39.5^{\circ} \mathrm{C}$ and fever duration of 24 to $36 \mathrm{~h}$. One child exhibited apathy, lethargy, and hand tremor.

\section{General treatment}

All patients received conventional treatment, including induction of vomiting, gastric lavage, catharsis, fluid infusion, and fasting from fats and oils, and underwent PE within 30 to $91 \mathrm{~h}$ of ingestion of $R$. communis.

\section{PE method}

PE was performed using a BM25 continuous blood purification machine (Baxter Corp., USA), with supporting extracorporeal circulation pipelines and P1 dry plasma separator (membrane area $0.3 \mathrm{~m}^{2}$, Fresenius SE \& Co. KgaA, Bad Homburg, Germany). Using a femoral vein catheter (Arrow Electronics, Inc., USA), $25 \mathrm{U} / \mathrm{mL}$ heparinized saline was infused to circulate the vascular access for $30 \mathrm{~min}$, then $100 \mathrm{~mL}$ pre-prepared red blood cell suspension (plasma-reduced blood), of the same blood type as the child, was injected into the vascular access and held there. The posterior substitution method was used. The exchange fluid was fresh frozen plasma of the same blood type as the child, and the exchange volume was 1440 to $1950 \mathrm{~mL}$, with a mean of $1781.43 \pm 168.27 \mathrm{~mL}$.

\section{Observation indicators}

The speed of blood flow (SBF), speed of exchange flow (SEF), isolating rate of blood plasma (IF), transmembrane pressure (TMP), venous pressure (VP), and heparin dose (HPD) were recorded every $15 \mathrm{~min}$. The plasma separation rate $(\%)=[(\mathrm{SEF} /(\mathrm{SBF} \times 60)] \times 100$. The mean arterial pressure (MAP), heart rate (HR), respiratory rate (RR), and pulse oxygen saturation $\left(\mathrm{SpO}_{2}\right)$ were monitored and recorded every $15 \mathrm{~min}$. The coagulation functions of the venous blood were monitored before and after PE.

\section{Statistical analysis}

The SPSS 11.0 statistical software was used for the statistical analysis. The measurement data are reported as means $\pm \mathrm{SD}$, the comparison of means at different times used the 
single-factor repeated-measuring analysis of variance, and the coagulation changes used the paired $t$-test, with the test level $(\alpha)$ set as 0.05 .

\section{RESULTS}

\section{General information}

All patients successfully completed PE. One child developed a rash $2 \mathrm{~h}$ after PE, and 2 children developed a rash during PE. The rashes all gradually disappeared $1 \mathrm{~h}$ after administration of promethazine hydrochloride and dexamethasone. After a 10-day hospitalization, all patients recovered and were discharged from the hospital. A 10-month follow-up revealed that none of the patients had systemic organ dysfunction or sequelae.

\section{Changes of PE parameters}

SBF was 50 to $80 \mathrm{~mL} / \mathrm{min}$, SEF was 600 to $800 \mathrm{~mL} / \mathrm{h}$, and IF was 12.5 to $19.05 \%$. The TMP and VP were slightly higher after 30 min of PE than at other times, without significant difference $(\mathrm{P}>0.05)$. The first HPD was $0.39 \pm 0.04 \mathrm{mg} / \mathrm{kg}$, and the maintenance HPD decreased gradually such that at $15 \mathrm{~min}$ before the end of PE, the HPD was significantly lower than that during the 15 to 75 min after $\mathrm{PE}$ was started $(\mathrm{P}<0.01$; Table 1$)$.

Table 1. Comparison of the plasma exchange parameters (means $\pm \mathrm{SD}, \mathrm{N}=7$ ).

\begin{tabular}{lcccccc}
\hline Time & SBF $(\mathrm{mL} / \mathrm{min})$ & SEF $(\mathrm{mL} / \mathrm{h})$ & IF $(\%)$ & TMP $(\mathrm{mmHg})$ & $\mathrm{VP}(\mathrm{mmHg})$ & $\mathrm{HPD} \mathrm{mg} \cdot \mathrm{kg}^{-1} \cdot \mathrm{h}^{-1}$ \\
\hline $15 \mathrm{~min}$ & $64.29 \pm 7.87$ & $600.00 \pm 0.00$ & $15.78 \pm 2.17$ & $88.57 \pm 24.10$ & $77.14 \pm 30.94$ & $0.40 \pm 0.05$ \\
$30 \mathrm{~min}$ & $69.29 \pm 1.89$ & $600.00 \pm 0.00$ & $14.44 \pm 0.42$ & $117.14 \pm 40.71$ & $104.29 \pm 30.47$ & $0.40 \pm 0.14$ \\
$45 \mathrm{~min}$ & $70.00 \pm 0.00$ & $600.00 \pm 0.00$ & $14.29 \pm 0.00$ & $104.29 \pm 11.34$ & $94.29 \pm 12.72$ & $0.38 \pm 0.14$ \\
$60 \mathrm{~min}$ & $70.00 \pm 0.00$ & $628.57 \pm 75.59$ & $14.97 \pm 1.80$ & $101.43 \pm 13.45$ & $92.71 \pm 9.39$ & $0.37 \pm 0.11$ \\
$75 \mathrm{~min}$ & $71.43 \pm 3.78$ & $671.43 \pm 95.12$ & $15.73 \pm 2.57$ & $104.29 \pm 7.87$ & $95.71 \pm 11.34$ & $0.35 \pm 0.11$ \\
$90 \mathrm{~min}$ & $71.43 \pm 3.78$ & $700.00 \pm 100.00$ & $16.41 \pm 2.75$ & $104.29 \pm 11.34$ & $98.57 \pm 10.69$ & $0.29 \pm 0.07$ \\
$105 \mathrm{~min}$ & $71.43 \pm 3.78$ & $700.00 \pm 100.00$ & $16.41 \pm 2.75$ & $102.86 \pm 17.04$ & $95.71 \pm 12.72$ & $0.28 \pm 0.07$ \\
$120 \mathrm{~min}$ & $71.43 \pm 3.78$ & $700.00 \pm 100.00$ & $16.41 \pm 2.75$ & $105.71 \pm 15.12$ & $92.86 \pm 13.80$ & $0.28 \pm 0.07$ \\
$135 \mathrm{~min}$ & $71.43 \pm 3.78$ & $700.00 \pm 100.00$ & $16.41 \pm 2.75$ & $105.71 \pm 16.18$ & $94.29 \pm 12.72$ & $0.25 \pm 0.04$ \\
$150 \mathrm{~min}$ & $71.43 \pm 3.78$ & $700.00 \pm 100.00$ & $16.41 \pm 2.75$ & $105.71 \pm 15.12$ & $92.86 \pm 13.80$ & $0.23 \pm 0.04$ \\
$165 \mathrm{~min}$ & $71.43 \pm 3.78$ & $700.00 \pm 100.00$ & $16.41 \pm 2.75$ & $100.00 \pm 18.28$ & $90.00 \pm 18.26$ & $0.22 \pm 0.03$ \\
$180 \mathrm{~min}$ & $71.43 \pm 3.78$ & $700.00 \pm 100.00$ & $16.41 \pm 2.75$ & $100.00 \pm 10.00$ & $88.57 \pm 10.69$ & $0.00 \pm 0.00$ \\
$\mathrm{P}$ & 0.116 & 0.031 & 0.171 & 0.400 & 0.359 & 0.000 \\
\hline
\end{tabular}

$\mathrm{SBF}=$ speed of blood flow; $\mathrm{SEF}=$ speed of exchange flow; $\mathrm{IF}=$ isolating rate of blood plasma; $\mathrm{TMP}=$ transmembrane pressure; VP = venous pressure; HPD = heparin dose.

\section{Changes of the vital signs during PE}

During PE, the patients' vital signs were stable: $\mathrm{MAP}, \mathrm{SpO}_{2}, \mathrm{HR}$, and RR exhibited no statistically significant difference at each time point $(\mathrm{P}>0.05$; Figures $1-4)$.

\section{Changes of coagulation function before and after PE}

The post-PE prothrombin time (PT) and international normalized ratio of PT (PT-INR) exhibited a trend of prolongation but without significant difference $(\mathrm{P}>0.05)$; the post-PE acti- 
vated partial thromboplastin time (APTT) and thrombin time (TT) were significantly longer (P $<0.05)$; and the post-PE fibrinogen was significantly reduced $(\mathrm{P}<0.01$; Table 2$)$.

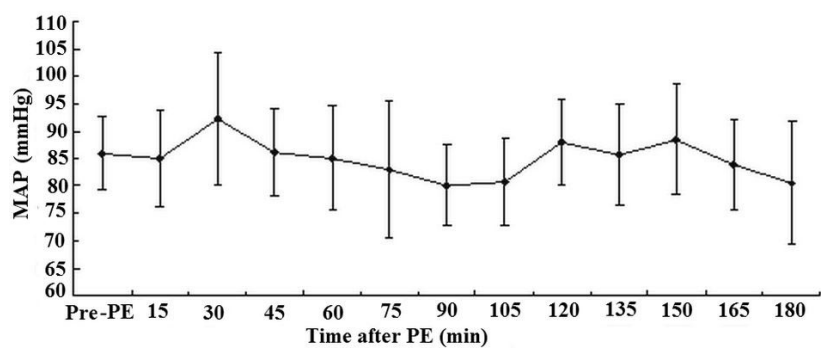

Figure 1. Changes of mean arterial pressure (MAP) in plasma exchange (PE) treatment.

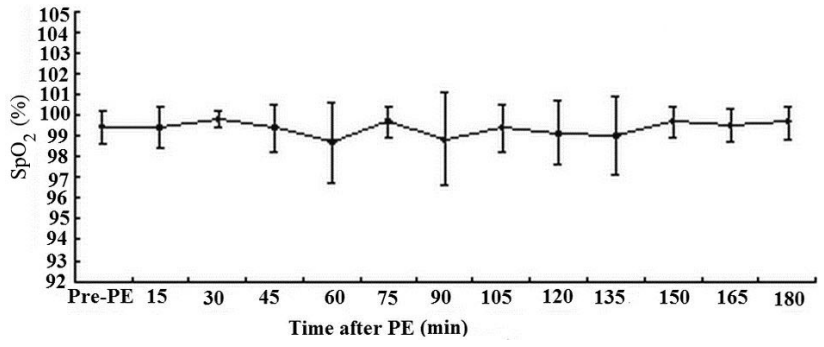

Figure 2. Changes of pulse oxygen saturation $\left(\mathrm{SpO}_{2}\right)$ in plasma exchange (PE) treatment.

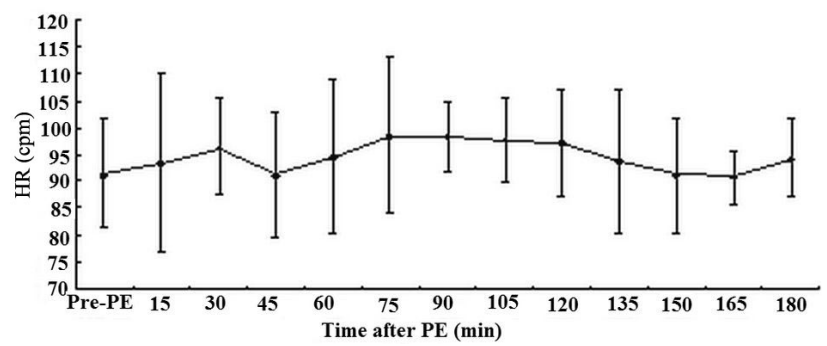

Figure 3. Changes of heart rate (HR) in plasma exchange (PE) treatment.

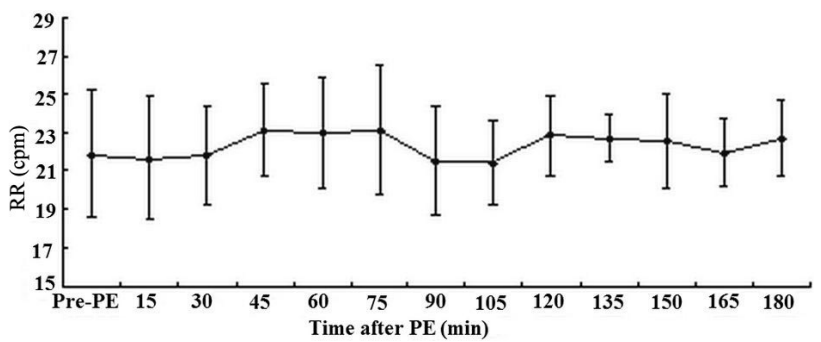

Figure 4. Changes of respiratory rate (RR) in plasma exchange (PE) treatment. 
Table 2. Changes of coagulation function before and after plasma exchange (PE) treatment (means $\pm \mathrm{SD}, \mathrm{N}=7$ ).

\begin{tabular}{lccccc}
\hline Time & PT $(\mathrm{s})$ & PT-INR & APTT $(\mathrm{s})$ & TT $(\mathrm{s})$ & FB $(\mathrm{g} / \mathrm{L})$ \\
\hline Pre-PE & $12.14 \pm 0.93$ & $1.04 \pm 0.08$ & $26.13 \pm 4.00$ & $16.17 \pm 0.93$ & $2.86 \pm 0.40$ \\
Post-PE & $13.90 \pm 2.28$ & $1.18 \pm 0.18$ & $68.26 \pm 32.30$ & $47.13 \pm 34.54$ & $1.83 \pm 0.34$ \\
T & -1.884 & -1.885 & -3.425 & -2.370 & 5.182 \\
P & 0.084 & 0.084 & 0.013 & 0.055 & 0.000 \\
\hline
\end{tabular}

$\mathrm{PT}=$ prothrombin time; PT-INR $=$ international normalized ratio of PT; APPT $=$ activated partial thromboplastin time; $\mathrm{TT}=$ thrombin time; $\mathrm{FB}=$ fibrinogen.

\section{DISCUSSION}

PE was initially used for the treatment of liver diseases, providing valuable time for autogenic liver cell repair and for patients awaiting liver transplantation, especially for patients with acute liver failure (Stenbøg et al., 2013). In recent years, with increased understanding of disease pathogenesis and PE technology, PE indications have gradually expanded into neurology, hematology, critical care medicine, rheumatology, dermatology, and other fields (Erkurt et al., 2013; Kaya et al., 2013), but experience in pediatric applications is limited. The most toxic ingredients in $R$. communis are ricin and ricinine (Brandon et al., 2012). Ricinine is water-soluble, with a relative molecular mass of 164.16 daltons; therefore, it can be eliminated through hemodialysis, hemofiltration, or peritoneal dialysis. However, ricin is a large protein molecule formed by the connection of an A-chain (RTA) and B-chain (RTB) through a disulfide bond (Balint, 1974; Challoner and McCarron, 1990; Roche et al., 2008), and its relative molecular weight is 65 kilodaltons. Such a large molecule cannot be eliminated through the above blood purification measures (convection and diffusion theory) and can only be cleared through PE. Although blood perfusion could broadly clear such toxins as ricin and ricinine, the adsorbent materials in this treatment would directly contact the patient's blood cells and could lead to dynamic instability of the blood during the procedure. Therefore, the risk of this approach is relatively large.

The most common complications reported with PE are nausea, vomiting, hypotension, abdominal pain, and pruritus (Erkurt et al., 2013), and rare complications are serum response and venous thrombosis (McGuckin et al., 2014). During PE, the MAP, HR, RR, and $\mathrm{SpO}_{2}$ of the children in our study were stable, with almost no significant changes in vital sign parameters at each time point. One of the 7 children exhibited a rash $2 \mathrm{~h}$ after PE, and 2 children exhibited rashes during PE. The rashes all gradually disappeared $1 \mathrm{~h}$ after the administration of promethazine hydrochloride and dexamethasone. The rest of the children had no discomfort, and all successfully completed the PE, indicating that with skilled and careful technical preparation, PE can be very safe in the rescue treatment of poisoning in children. The children in the study group underwent PE before significant organ dysfunction appeared, and the general condition of all the children was good, which contributed to PE safety. If the PE had been performed in the presence of significant organ dysfunction or circulatory failure, the risk would have increased, and the final prognosis would have been affected.

Anticoagulation is the key to successful blood purification (Naumnik et al., 2009; Shen and Winkelmayer, 2012). If anticoagulation is not adequate to obtain sufficient heparinization of the systemic blood, the TMP and VP might abnormally elevate, causing clotting of the filters and piping. An excessively high TMP could also cause hemolysis of the red blood cells. However, the opposite situation of excessive anticoagulation due to an excessive HPD would lead to bleeding. In our research, the initial HPD for the 7 children was $0.39 \pm 0.04 \mathrm{mg} /$ 
$\mathrm{kg}$, and maintenance doses were $0.40 \pm 0.05$ to $0.22 \pm 0.03 \mathrm{mg} \cdot \mathrm{kg}^{-1} \cdot \mathrm{h}^{-1}$, with a total dose of 1.33 $\pm 0.39 \mathrm{mg} / \mathrm{kg}$. The HPD was generally larger than that given to adults. No hemolysis occurred during the PE. The post-PE APTT, and TT prolonged to 2-3 times their values pre-PE, but no bleeding phenomena were seen in the skin puncture site or internal organs, and $8 \mathrm{~h}$ later, all the indicators returned to normal. This suggests that the children were in a growth and development period, with unstable coagulation function; therefore, the HPD required individualization. During the PE process, the TMP, VP, and color of the filters should be closely observed, and coagulation function should be closely monitored to prevent excessive anticoagulation-induced bleeding and insufficient coagulation-induced red blood cell destruction and hemolysis.

Regarding TMP and SBF, the TMP should be maintained at $<100 \mathrm{mmHg}$ for adults to prevent hemolysis, and the $\mathrm{SBF}$ must be $>50 \mathrm{~mL} / \mathrm{min}$ to avoid coagulation inside the hollow fibers of the membrane. The ideal SBF might be 100 to $150 \mathrm{~mL} / \mathrm{min}$. Because central veins are smaller in children, a central venous catheter with a small diameter must be used. In this research, an 8-Fr central venous catheter was selected, with the SBF maintained at 60 to 70 $\mathrm{mL} / \mathrm{min}$. The TMP and VP at $30 \mathrm{~min}$ were $117.14 \pm 40.71$ and $104.29 \pm 30.47 \mathrm{mmHg}$, respectively, and were slightly higher than those at the other time points. At other time points, the TMP was stable at approximately $100 \mathrm{mmHg}$, the VP was stable at approximately $95 \mathrm{mmHg}$, and the TMP was slightly higher than that of an adult. The higher TMP might have occurred because the membrane area of the child-type plasma separator is smaller than that used for adults, causing the blood to flow faster inside the hollow fibers. However, during the PE, no hemolysis or coagulation occurred, suggesting that when applying PE to children and closely monitoring coagulation functions, it is unnecessary to pursue a very low TMP, or use excessive anticoagulant, which must be avoided to prevent bleeding.

To improve exchange efficiency and save the plasma, the posterior exchange method of $\mathrm{PE}$ is often used. This requires more anticoagulation than the prior exchange mode; thus, the dose of anticoagulant used is relatively large. In this circumstance, we considered that it would be more important to control the SEF and IF. If the SEF was too fast, and the IF was too large, the blood would gradually thicken when flowing from the arterial end to the venous end inside the plasma separator, and the blood flow rate would gradually slow down, which could easily result in coagulation and erythrocyte rupture (Basic-Jukic et al., 2005). In this research, the patients' SEF was maintained at 600 to $700 \mathrm{~mL} / \mathrm{h}$, and the IF was controlled at approximately $15 \%$ during the PE process. No abnormal elevation of TMP and VP occurred, and no patient exhibited coagulation or hemolysis, suggesting the importance of controlling the SEF and IF and also suggesting that the amount of anticoagulant was appropriate.

In summary, for children with acute poisoning, especially from biological toxins with complex composition, larger molecular weight, and high affinity for plasma proteins (e.g., fish guts, $R$. communis, snake bites, and poisonous mushrooms), PE is safe and effective for purging toxins from the blood, tissues, and organs, and should be widely applied. When considering PE, it is unnecessary to wait for clinical organ failure to occur; PE should be performed as soon as possible so as to remove toxins and reduce subsequent damage, thus reducing mortality and sequelae, and improving the success rate.

\section{REFERENCES}

Assiri AS (2012). Ricin poisoning causing death after ingestion of herbal medicine. Ann. Saudi Med. 32: 315-317. Audi J, Belson M, Patel M, Schier J, et al. (2005). Ricin poisoning: a comprehensive review. JAMA 294: 2342-2351. 
Balint GA (1974). Ricin: the toxic protein of castor oil seeds. Toxicology 2: 77-102.

Basic-Jukic N, Kes P, Glavas-Boras S, Brunetta B, et al. (2005). Complications of therapeutic plasma exchange: experience with 4857 treatments. Ther. Apher. Dial. 9: 391-395.

Brandon DL, Korn AM and Yang LL (2012). Detection of ricin contamination in liquid egg by electrochemiluminescence immunosorbent assay. J. Food Sci. 77: T83-T88.

Buonocore C, Alipour M, Omri A, Pucaj K, et al. (2011). Treatment of ricin A-chain-induced hepatotoxicity with liposome-encapsulated N-acetylcysteine. J. Drug Target. 19: 821-829.

Challoner KR and McCarron MM (1990). Castor bean intoxication. Ann. Emerg. Med. 19: 1177-1183.

Erkurt MA, Kuku I, Kaya E, Ozgen U, et al. (2013). Therapeutic plasma-exchange in hematologic disease: results from a single center in Eastern Anatolia. Transfus. Apher. Sci. 48: 335-339.

Hu WG, Yin J, Chau D, Negrych LM, et al. (2012). Humanization and characterization of an anti-ricin neutralization monoclonal antibody. PLoS One 7: e45595.

Inoue D, Togami K, Shimoike N, Tamura R, et al. (2010). Early diagnosis and successful treatment of catastrophic antiphospholipid syndrome complicated by multiple organ failure. Nihon Rinsho Meneki Gakkai Kaishi 33: 24-30.

Kaya E, Keklik M, Sencan M, Yilmaz M, et al. (2013). Therapeutic plasma exchange in patients with neurological diseases: multicenter retrospective analysis. Transfus. Apher. Sci. 48: 349-352.

Lim H, Kim HJ and Cho YS (2009). A case of ricin poisoning following ingestion of Korean castor bean. Emerg. Med. J. 26: 301-302.

McGuckin S, Westwood JP, Webster H, Collier D, et al. (2014). Characterization of the complications associated with plasma exchange for thrombotic thrombocytopaenic purpura and related thrombotic microangiopathic anaemias: a single institution experience. Vox Sang. 106: 161-166.

Musshoff F and Madea B (2009). Ricin poisoning and forensic toxicology. Drug Test. Anal. 1: 184-191.

Nakae H, Igarashi T and Tajimi K (2012). Selective plasma exchange with dialysis in patients with acute liver failure. Ther. Apher. Dial. 16: 467-471.

Naumnik B, Pawlak K and Myśliwiec M (2009). Different effects of enoxaparin and unfractionated heparin on some thrombogenesis markers during hemodialysis: a cross-over study. Thromb. Res. 123: 631-636.

Qiu HM, Zheng SC, Wan WG and Zou HJ (2011). Meta-analysis of the effectiveness of plasma exchange in treatment of severe and acute organophosphate poisoning. Zhonghua Lao Dong Wei Sheng Zhi Ye Bing Za Zhi 29: 779-781.

Qu L, Kiss JE, Dargo G and Carcillo JA (2011). Outcomes of previously healthy pediatric patients with fulminant sepsisinduced multisystem organ failure receiving therapeutic plasma exchange. J. Clin. Apher. 26: 208-213.

Roche JK, Stone MK, Gross LK, Lindner M, et al. (2008). Post-exposure targeting of specific epitopes on ricin toxin abrogates toxin-induced hypoglycemia, hepatic injury, and lethality in a mouse model. Lab. Invest. 88: 1178-1191.

Schutt RC, Ronco C and Rosner MH (2012). The role of therapeutic plasma exchange in poisonings and intoxications. Semin. Dial. 25: 201-206.

Shen JI and Winkelmayer WC (2012). Use and safety of unfractionated heparin for anticoagulation during maintenance hemodialysis. Am. J. Kidney Dis. 60: 473-486.

Stenbøg P, Busk T and Larsen FS (2013). Efficacy of liver assisting in patients with hepatic encephalopathy with special focus on plasma exchange. Metab. Brain Dis. 28: 333-335. 